LA W RENCE LIVERMORE NATIO N A L LABORATORY

Progress Toward Ignition on the National Ignition Facility

R. L. Kauffman

October 25, 2011 
This document was prepared as an account of work sponsored by an agency of the United States government. Neither the United States government nor Lawrence Livermore National Security, LLC, nor any of their employees makes any warranty, expressed or implied, or assumes any legal liability or responsibility for the accuracy, completeness, or usefulness of any information, apparatus, product, or process disclosed, or represents that its use would not infringe privately owned rights. Reference herein to any specific commercial product, process, or service by trade name, trademark, manufacturer, or otherwise does not necessarily constitute or imply its endorsement, recommendation, or favoring by the United States government or Lawrence Livermore National Security, LLC. The views and opinions of authors expressed herein do not necessarily state or reflect those of the United States government or Lawrence Livermore National Security, LLC, and shall not be used for advertising or product endorsement purposes.

This work performed under the auspices of the U.S. Department of Energy by Lawrence Livermore National Laboratory under Contract DE-AC52-07NA27344. 


\section{Progress Toward Ignition on the National Ignition Facility ${ }^{1}$ Robert Kauffman \\ Lawrence Livermore National Laboratory}

The National Ignition Facility (NIF) is a 192-beam laser facility at Lawrence Livermore National Laboratory (LLNL) completed in 2009. NIF is the world's most energetic laser facility for research in Inertial Confinement Fusion (ICF), High Energy Density Science (HEDS) and other stockpile stewardship research, advanced energy production, and basic science. ${ }^{1}$ NIF is fully operational and has demonstrated its ability to meet its design goals of 1.8 MJ laser energy. ${ }^{2}$ Ignition experiments are under way and significant progress has been made toward its goal of ignition and burn in the laboratory.

The ignition research is conducted as part of the National Ignition Campaign (NIC), an enhanced management program by the National Nuclear Security Administration (NNSA). NIC is a national partnership of LLNL, Los Alamos National Laboratory (LANL), Sandia National Laboratories (SNL), the University of Rochester Laboratory for Laser Energetics (UR-LLE), General Atomics (GA) and a number of other collaborators including Lawrence Berkeley National Laboratory (LBL), the Massachusetts Institute of Technology (MIT), the U.K. Atomic Weapons Establishment (AWE), and the French Atomic Energy Commission (CEA). The goal of the NIC program is to demonstrate a reliable and repeatable ignition platform and develop NIF as a user facility for its multiple missions. NIC encompasses all of the capabilities required for ignition experiments including development of the diagnostics, targets, target cryogenic system, phase plates and other optics, and personnel and environmental protection equipment. Experiments on OMEGA at UR-LLE, NIF and other facilities provide the technical basis for ignition experiments.

The principal approach to ignition on NIF is indirect drive. ${ }^{3}$ A schematic of an ignition target is shown in Figure 1. The laser beams are focused through laser entrance holes at each end of a high- $Z$ cylindrical case, or hohlraum. The lasers irradiate the hohlraum walls producing X-rays that ablate and compress the fuel capsule in the center of the hohlraum. The hohlraum is made of $\mathrm{Au}, \mathrm{U}$, or other high- $\mathrm{Z}$ material. For ignition targets, the hohlraum is $\sim 0.5 \mathrm{~cm}$ diameter by $\sim 1 \mathrm{~cm}$ in length. The hohlraum absorbs the incident laser energy producing $\mathrm{x}$-rays for symmetrically imploding the capsule. The fuel capsule is a 2-mm-diameter spherical shell of $\mathrm{CH}, \mathrm{Be}$, or $\mathrm{C}$ filled with DT fuel. The DT fuel is in the form of a cryogenic layer on the inside of the capsule. X-rays ablate the outside of the capsule, producing a spherical implosion. The imploding shell stagnates in the center, igniting the DT fuel.

NIC has overseen installation of all of the hardware for performing ignition experiments, including commissioning of approximately 50 diagnostic systems in NIF. The diagnostics measure scattered optical light, $\mathrm{x}$-rays from the hohlraum over the energy range from 100 $\mathrm{eV}$ to $500 \mathrm{keV}$, and $\mathrm{x}$-rays, neutrons, and charged particles from the implosion. An example of a diagnostic is the Magnetic Recoil Spectrometer (MRS) built by a collaboration of scientists from MIT, UR-LLE, and LLNL shown in Figure 2. MRS measures the neutron spectrum from the implosion, providing information on the neutron yield and areal density that are metrics of the quality of the implosion.

\footnotetext{
${ }^{1}$ This work performed under the auspices of the U.S. Department of Energy by Lawrence Livermore National Laboratory under Contract DE-AC52-07NA27344.
} 
Experiments on NIF extend ICF research to unexplored regimes in target physics. NIF can produce more than 50 times the laser energy and more than 20 times the power of any previous ICF facility. Ignition scale hohlraum targets are three to four times larger than targets used at smaller facilities, and the ignition drive pulses are two to five times longer. The larger targets and longer pulse lengths produce unique plasma conditions for laser-plasma instabilities that could reduce hohlraum coupling efficiency. Initial experiments have demonstrated efficient coupling of laser energy to X-rays. X-ray drive greater than $300 \mathrm{eV}$ has been measured in gas-filled ignition hohlraums and shows the expected scaling with laser energy and hohlraum scale size. ${ }^{4}$

Experiments are now optimizing capsule implosions for ignition. Ignition conditions require assembling the fuel with sufficient density and temperature for thermonuclear burn. X-rays ablate the outside of the capsule, accelerating and spherically compressing the capsule for assembling the fuel. The implosion stagnates, heating the central core and producing a hot spot that ignites and burns the surrounding fuel. The four main characteristics of the implosion are shell velocity, central hot spot shape, fuel adiabat, and mix. Experiments studying these four characteristics of implosions are used to optimize the implosion.

Integrated experiments using cryogenic fuel layer experiments demonstrate the quality of the implosion as the optimization experiments progress. The final compressed fuel conditions are diagnosed by measuring the x-ray emission from the hot core and the neutrons and charged particles produced in the fusion reactions. Metrics of the quality of the implosion are the neutron yield and the shell areal density, as well as the size and shape of the core. The yield depends on the amount of fuel in the hot core and its temperature and is a gauge of the energy coupling to the fuel. The areal density, the density of the fuel times its thickness, diagnoses the fuel assembly, which is measured using the fraction of neutrons that are down scattered passing through the dense shell.

The yield and fraction of down scattered neutrons, or shell rho-r, from the cryogenic layered implosions are shown in Figure 3. The different sets of data represent results after a series of implosion optimization experiments. Both yield and areal density show significant increases as a result of the optimization. The experimental Ignition Threshold Factor (ITFX) is a measure of the progress toward ignition. ${ }^{5}$ ITFX is analogous to the Lawson Criterion in Magnetic Fusion. Implosions have improved by over a factor of 50 since the first cryogenic layered experiments were done in September 2010. This increase is a measure of the progress made toward the ignition goal in the past year. Optimization experiments are planned in the coming year for continued improvement in implosion performance to achieve the ignition goal.

In summary, NIF has made significant progress toward ignition in the 30 months since project completion. Diagnostics and all of the supporting equipment are in place for ignition experiments. The Ignition Campaign is under way as a national collaborative effort of all the NNSA science laboratories as well as international partners. Experiments have shown that hohlraum conditions can produce $\mathrm{x}$-ray drive temperatures needed for ignition with low levels of preheat. Cryogenic implosions have shown remarkable progress during the first year of experiments, and continued improvements are planned in the coming year to attain the ignition goal. 


\section{Typical NIF ignition target}

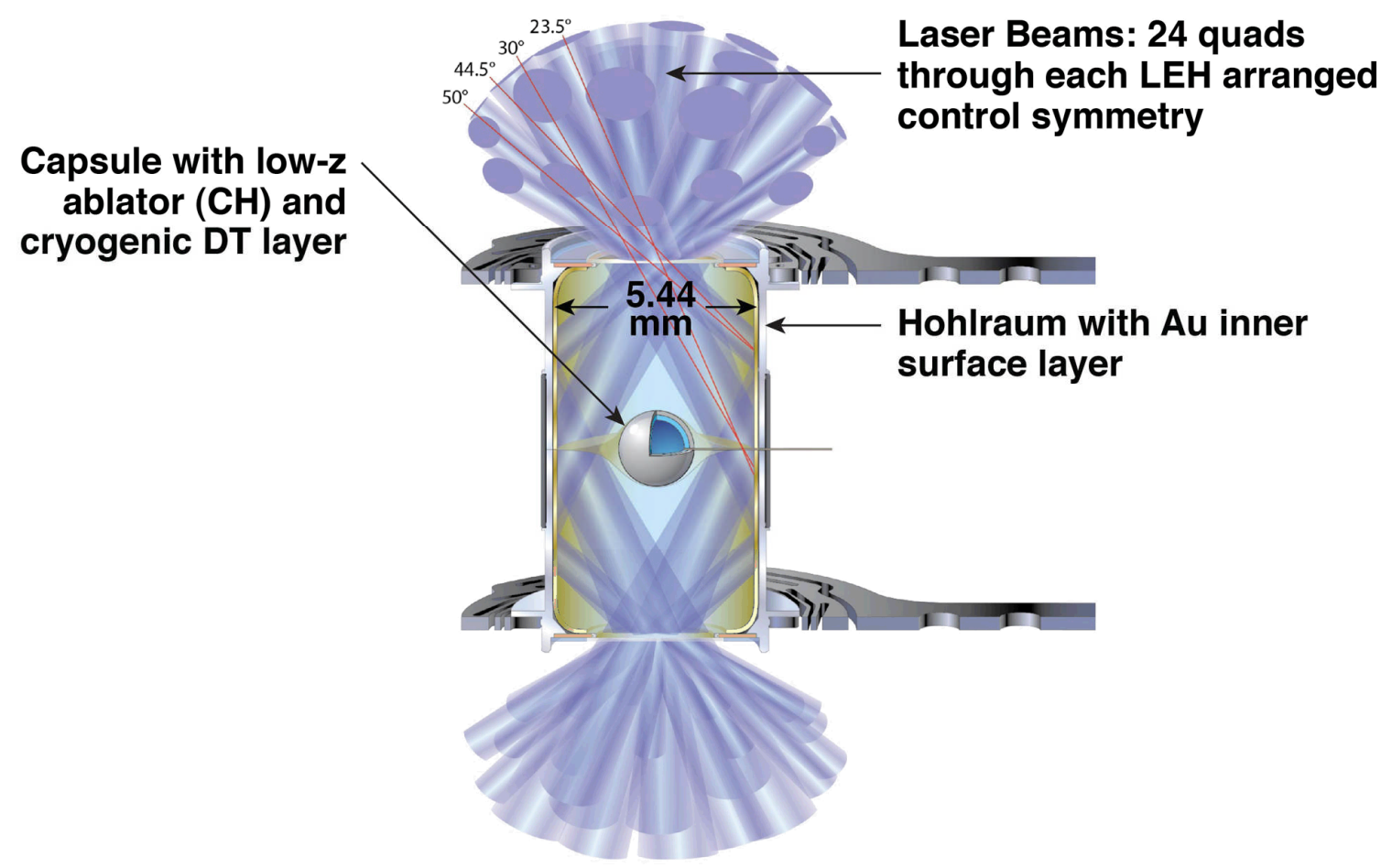

Figure 1. Schematic of a NIF indirect-drive hohlraum target. The lasers irradiate the high$\mathrm{Z}$ hohlraum wall, imploding the spherical capsule in the center containing the fusion fuel.

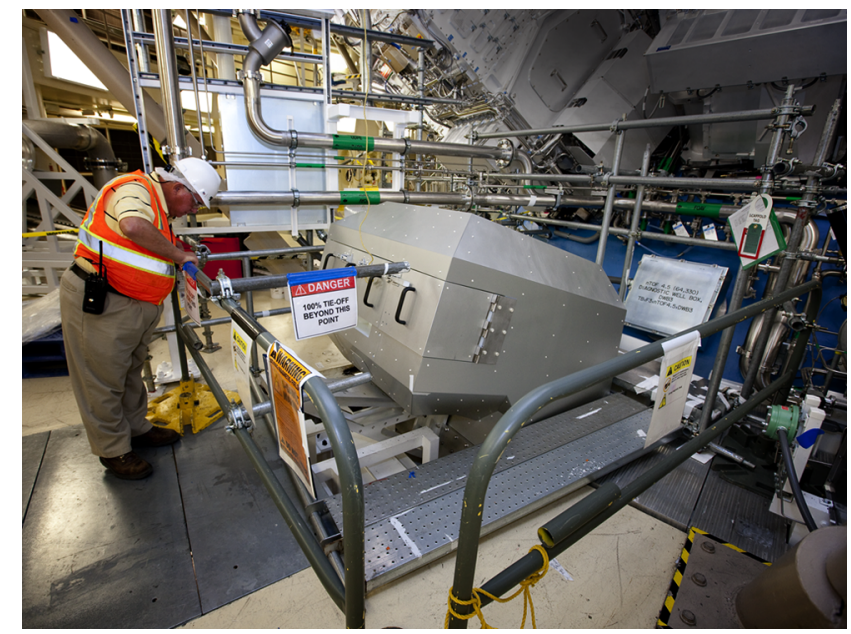

Figure 2. The Magnetic Recoil Spectrometer (MRS). The MRS fielded by a team from MIT, UR-LLE and LLNL, measures the neutron spectrum from an implosion to determine the yield and areal density. 


\section{Layered target ITFX}

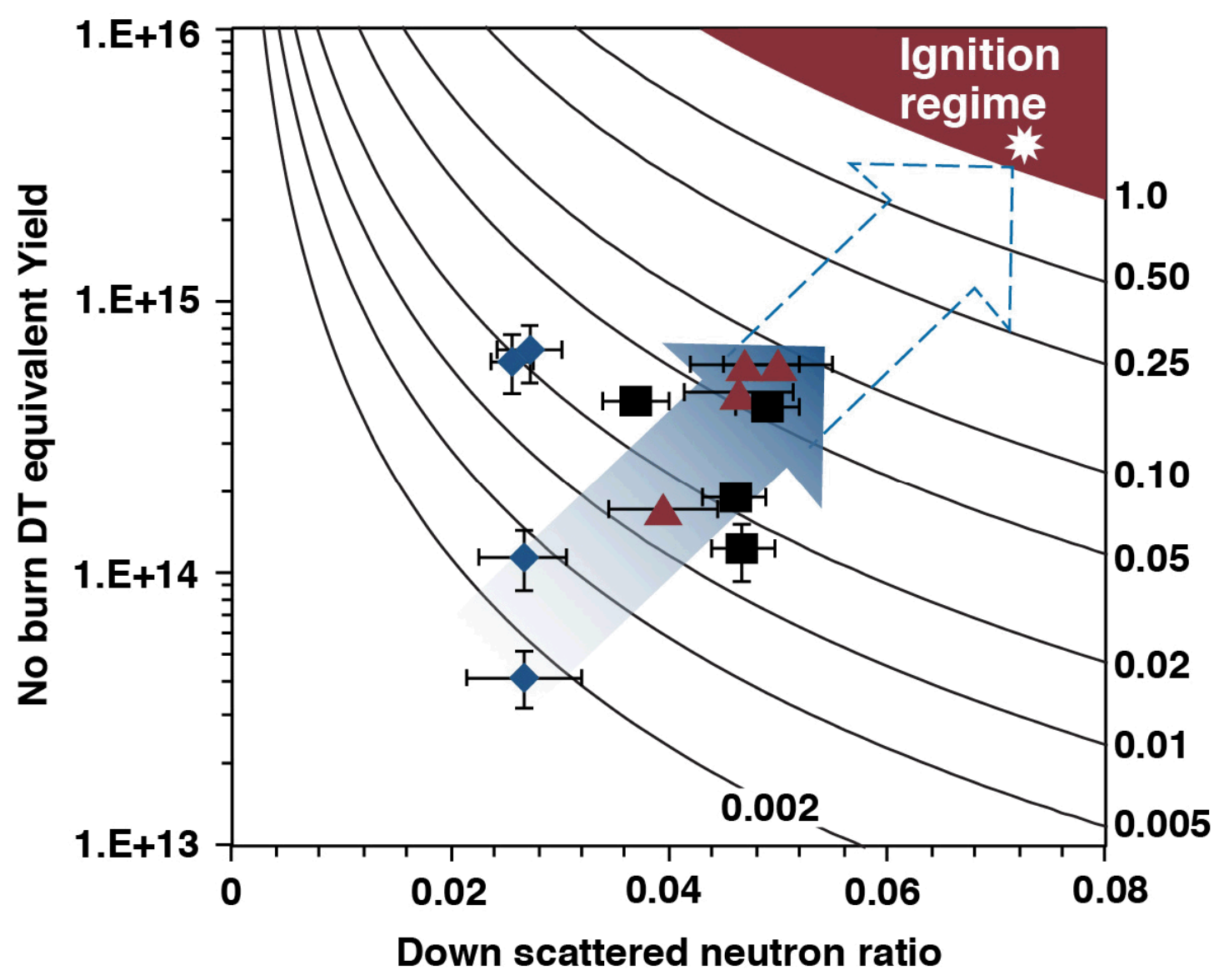

NIF-1011-23460pb

Figure 3. Results showing the neutron yield and areal density from layered cryogenic implosions. The progress toward ignition is shown by the improvement in ITFX.

${ }^{1}$ E. I. Moses, J. Phys.: Conf. Series 112, 012003 (2008).

2 C. A. Haynam et al., Appl. Opt. 46, 3276 (2007).

3 J.D. Lindl, Inertial confinement fusion: the quest for ignition and energy gain using indirect drive (American Institute of Physics Press, New York, 1998).

${ }^{4}$ S. H. Glenzer et al., Phys. Rev. Lett. 106, 085004 (2011).

${ }^{5}$ M. J. Edwards et al., Phys. Plasmas 18, 051003-1 (2011). 